\title{
EFFECT OF STARVATION AND REFEEDING DIETS CONTAINING DIFFERENT PROTEIN LEVELS ON COMPENSATORY GROWTH AND HISTOPATHOLOGICAL CHANGES OF NILE TILAPIA (OREOCHROMIS NILOTICUS)
}

\author{
Abeer E. Aziza'; W.F. Awadin'; E. Zahran ${ }^{3}$ and T.I. Mohamed ${ }^{1}$ \\ ${ }^{1}$ Department of Nutrition and Nutritional Deficiency Diseases, Faculty of Veterinary Medicine, \\ Mansoura University, 35516 Mansoura, Egypt. \\ ${ }^{2}$ Department of Pathology, Faculty of Veterinary Medicine, Mansoura University, 35516 Mansoura, \\ Egypt. \\ ${ }^{3}$ Department of Internal Medicine, Infections and Fish Diseases, Faculty of Veterinary Medicine, \\ Mansoura University, Mansoura 35516, Egypt. \\ Corresponding Author. Abeer Aziza, Department of Nutrition and Nutritional Deficiency Diseases, \\ Faculty of Veterinary Medicine, Mansoura University, 35516 Mansoura, Egypt.
}

(Received 9/7/2015, accepted 30/8/2015)

\section{SUMMARY}

\begin{abstract}
$\mathrm{T}$ his study was conducted to evaluate the effect of deprivation and refeeding of diets containing different levels of protein on growth performance, liver histopathological changes and intestinal morphometric in Nile tilapia (Oreochromis niloticus). One hundred and twenty Nile tilapia fish weighing $35 \pm 0.5 \mathrm{~g}$ were randomly distributed into 12 aquarium tanks ( $10 \mathrm{fish} / \mathrm{tank}$ ). Triplicate tanks were assigned for each dietary regimen. Four groups were firstly fasted for 8 weeks then refed for the following 4 weeks on diets containing different levels of protein $(26 \%, 28 \%, 30 \%$, and $32 \%)$. Fish were weighed during starvation and refeeding period. The body weight (BW) of fish fed diet containing $28 \%$ \& $30 \%$ were significantly higher than that of other groups. Condition factor (CF) of fish fed diet containing $30 \& 32 \% \mathrm{CP}$ was higher than that of other groups. Liver of Nile tilapia during starvation showed small hepatocytes. Refeeding results in gradual increase in size of hepatocytes of fish in different groups and with increased villous height, perimeter, area and number of goblet cells (GCs). Our results indicate that a diet containing 28 , $30 \%$ of CP could be optimal in relative growth compensation after starvation. CF revealed better values in fish fed diets containing $30 \& 32 \%$ of CP. Moreover, starved Nile tilapia has the ability to recover the normal liver histology after period of refeeding.
\end{abstract}

Keywords: Nile tilapia, dietary protein levels, starvation, refeeding, growth performance, liver histopathology, intestinal morphometric.

\section{INTRODUCTION}

Nile tilapia is considered the best species for culture due to their high tolerance to adverse environmental conditions, relatively fast growth rate and they easily bred (EL-Sayed, 2006). Production of farmed tilapia has increased from 1,189,959 tons in 2000 to 3,096,935 tons in 2009, representing 8.6\% of total farmed finfish (FAO, 2009). Additionally, Nile tilapia represents about $82.1 \%$ of total production of farmed tilapia (FAO, 2009). Feed is the most expensive component of aquaculture and counting for $40-60 \%$ of the operating cost depending on the intensity of production thus overfeeding would mean economic waste and could adversely affect water quality by leaching of the nutrients (Marimuthu et al., 2010). Additionally, dietary protein requirements of a fish species are of fundamental importance in aquaculture, because dietary protein significantly influences growth, survival and yield of fish as well as economics of a farming industry (Islam and Tanaka, 2004). Short-term or multiple periods of feed deprivation then re-feeding could increase feed efficiency and growth in various fish species (Tian and Qin 2003; Zhu et al., 2004). Moreover, Davis and Gaylord (2011) reported that fish able to cope with long period of feed restriction due to limitation in forage base, weather events and during certain phases 
of their reproductive cycle. Compensatory growth is defined as a phase of unusually rapid growth of fish resulting from refeeding after fasting or undernutrition and can be used as a management tool to improve growth rates and feed efficiency and to reduce feed cost (Hayward et al., 1997). Achieving compensatory growth of fish could have several advantages for aquaculture as saving feed and labor costs, reducing water pollution during starvation, improving feeding activity shortly after refeeding, and improving efficiency of fish production (Cho et al., 2006). Histological changes occur in the gut and liver, and cell degeneration in the digestive tract indicates starvation (Wang et al., 2006). Intestine is able to respond to changes in the diet by altering its weight, length, absorptive area and rate of enterocyte turnover (Bedford, 1996). Moreover, gut length, intestinal folds and microvillus length can decrease during food deprivation (Rios et al., 2004). Therefore, the objective of this research was to evaluate the effect of feeding diets containing different levels of dietary protein of Nile tilapia on growth performance and histopathological changes during fasting and refeeding period.

\section{MATERIALS AND METHODS}

\section{Experimental design and diet preparation:}

One hundred twenty unsexed Nile tilapia (average BW 35 $0.5 \mathrm{~g}$ ) were randomly divided into 12 glass aquaria ( $80 \mathrm{~cm}$ length, $35 \mathrm{~cm}$ width $\& 40 \mathrm{~cm}$ height), 10 fish in each. All Nile tilapia fish were acclimated 2 weeks and fed twice a day on diet containing $32 \% \mathrm{CP}$, and $3000 \mathrm{kcal} \mathrm{DE} / \mathrm{kg}$ according to NRC (1993) (Table 1). After 2 weeks of acclimation, all Nile tilapia fish were starved for 8 weeks. After starvation period four isocaloric $(3000 \mathrm{kcal} \mathrm{DE} / \mathrm{kg})$ experimental diets were formulated with different protein levels $(26 \%, 28 \%, 30 \%$, and $32 \%)$ and fed for 4 weeks. Each diet was fed to the tilapia fish in triplicate aquaria. The experiment lasted for 12 weeks and was divided in two periods, a starvation period ( 8 weeks) and a refeeding period (4 weeks). The weight and length of tilapia fish were determined during starvation and refeeding period.

\section{Histological examination:}

For histological morphometric analysis, tissue specimens were collected from fundic stomach, proximal, middle and distal intestine and liver and subsequently fixed in $10 \%$ buffered neutral formalin for routine histological process. Paraffin blocks from all organs were cut at $(4 \mu \mathrm{m})$ and stained with hematoxylin and eosin (H\&E). Additional sections from proximal, middle and distal intestine were stained with Alcian blue to stain goblet cells (GCs). Images of the examined organs were captured by an Olympus BX41 microscope supplied with a DVC 1300C color digital camera. Sections stained with H\&E stain were applied for histometric measurements (thickness of mucosa and muscular coat) of fundus region of stomach using an image analysis (image $J=$ http://imagej.en.softonic.com). Measurements in proximal, middle and distal intestine included villous height (from top to the base of the mucosal fold), perimeter and area (area within the perimeter for each fold), width (the maximum width of the fold along a line perpendicular to the fold height) and number of GCs. Values of the previously measured parameters were the means from the highest 10 vertically oriented folds per section. In liver, hepatocytes/nuclear ratio $(\mathrm{H} / \mathrm{N})$ was estimated in 50 hepatocytes per section.

\section{Statistical analysis:}

The results were subjected to a one-way ANOVA to test the effect of different dietary CP levels on BW and length during refeeding period after starvation period. Data were analyzed using statistical SPSS v20 (SPSS Inc., Chicago, IL, USA). Differences between means were compared using Duncan's multiple range test at significance of differences $(p<0.05)$ among dietary treatments.

\section{RESULTS AND DISCUSSION}

\section{Growth performance and condition factor $(\mathrm{CF})$}

The effect of different dietary protein levels on growth performance and body condition of starved fish and after refeeding is present in (Figure 1). Body weight of fish fed diet supplemented with 28 \& $30 \%$ CP was significantly higher than that of other groups. The length of fish supplemented with $32 \%$ was significantly lower than that of other experimental groups. CF showed higher significance in fish fed $30 \& 32 \%$ CP diets compared to other groups. 


\section{Egyptian J. Nutrition and Feeds (2015)}

Comparison of growth performance and condition factor between starved fish and refeeding fish at the same group are shown in (Table 2). Average BW was significantly higher in refeeding groups in relation to starving period. The lengths of refeeding fish fed 30 and $32 \% \mathrm{CP}$ diets were significantly lower than starved fish. However, there were no significant differences of length between starved and refeeding fish fed diets containing 26, and 28\% CP. Fish fed diet containing 26\% CP showed significant decrease $(\mathrm{p}<0.05)$ in CF compared to starved control group. However, CF of fish fed diet contained $28,30 \%$ showed a significant increase during refeeding compared to the starved fish. Interestingly, $\mathrm{CF}$ of fish fed $32 \% \mathrm{CP}$ showed very high level that reflects a worse indication on utilizing the feed.

Table (1): Ingredients and chemical composition \% of experimental diets.

\begin{tabular}{lcccc}
\hline Ingredients & \multicolumn{4}{c}{ Dietary treatments } \\
\cline { 2 - 4 } & $26 \% \mathrm{CP}$ & $28 \% \mathrm{CP}$ & $30 \% \mathrm{CP}$ & $32 \% \mathrm{CP}$ \\
\hline Yellow corn (8.5\%) & 47.7 & 45 & 43.5 & 31.7 \\
Soybean meal (44\%) & 19 & 19 & 21.7 & 32 \\
Fish meal & 18 & 20 & 22.5 & 20.5 \\
Corn gluten & 1 & 3 & 2 & 0 \\
Oil & 5 & 3.7 & 3 & 2.5 \\
Wheat ran & 8 & 8 & 6 & 12 \\
Mineral and vitamin premix* & 1 & 1 & 1 & 1 \\
Salt & 0.3 & 0.3 & 0.3 & 0.3 \\
Chemical composition & & & & 31.96 \\
CP\% & 25.94 & 28.20 & 29.95 & 3027 \\
DE (Kg/kg) & 3017 & 3020 & 3016 & 1.501 \\
Ca\% & 1.017 & 1.121 & 1.255 & 1.026 \\
P\% & 0.873 & 0.932 & 0.989 & \\
\hline
\end{tabular}

*Trace minerals \& vitamins premixes were prepared to cover the levels of the microminerals \&vitamins for tilapia fish as recommend-ed by (NRC, 1993).Vitamins premix (IU or mg/kg diet); vit. A 5000, Vit. D3 1000, vit. E 20, vit. k3 2, vit. B1 2, vit. B2 5, vit. B6 1.5, vit. B12 0.02, Pantothenic acid 10, Folic acid 1, Biotin 0.15, Niacid 30. Mineral mixture (mg/kg diet); Fe 40, Mn 80, Cu 4, Zn 50, I 0.5, Co.

Table (2): Comparison between starved control and refeeding group fed supplemented different level of CP during the period of starvation and refeeding

\begin{tabular}{lcccccccc}
\hline \multirow{2}{*}{ Parameters } & \multicolumn{7}{c}{ Dietary protein level } \\
\cline { 2 - 8 } & Control & Refeeding & Control & refeeding & control & refeeding & control & refeeding \\
\cline { 2 - 8 } & \multicolumn{2}{c}{$26 \%$} & \multicolumn{2}{c}{$28 \%$} & \multicolumn{2}{c}{$30 \%$} & $32 \%$ \\
\hline BW & $30.6128^{\mathrm{b}}$ & $39.3165^{\mathrm{a}}$ & $34.089^{\mathrm{b}}$ & $38.664^{\mathrm{a}}$ & $38.250^{\mathrm{b}}$ & $44.152^{\mathrm{a}}$ & $28.428^{\mathrm{b}}$ & $40.455^{\mathrm{a}}$ \\
& \pm 2.15173 & \pm 3.72279 & \pm 1.876 & \pm 2.402 & \pm 3.033 & \pm 2.313 & \pm 2.321 & \pm 2.394 \\
BWG & 14.1940 & 18.6207 & $11.183^{\mathrm{b}}$ & $20.745^{\mathrm{a}}$ & 18.990 & 19.271 & $14.390^{\mathrm{b}}$ & $18.078^{\mathrm{a}}$ \\
& \pm 2.73792 & \pm 3.54650 & \pm 2.597 & \pm 4.643 & \pm 3.221 & \pm 3.922 & \pm 1.614 & \pm 3.486 \\
Length & 12.6423 & 13.5775 & 13.250 & 13.544 & $14.238^{\mathrm{a}}$ & $13.275^{\mathrm{b}}$ & $12.375^{\mathrm{a}}$ & $11.054^{\mathrm{b}}$ \\
& \pm .33936 & \pm 0.40848 & \pm 0.248 & \pm 0.257 & \pm 0.288 & \pm 0.362 & \pm 0.307 & \pm 0.856 \\
CF & $1.4663^{\mathrm{a}}$ & $1.4115^{\mathrm{b}}$ & $1.409^{\mathrm{b}}$ & $1.474^{\mathrm{a}}$ & 1.461 & 1.502 & $1.383^{\mathrm{b}}$ & $4.102^{\mathrm{a}}$ \\
& \pm 0.04016 & \pm 0.01343 & \pm 0.024 & \pm 0.019 & \pm 0.024 & \pm 0.022 & \pm 0.024 & \pm 0.773 \\
\hline
\end{tabular}

Different superscripts in the same row indicate significant $(P \leq 0.05)$ difference between groups. WG: weight gain rate $(\%)=100 \cdot($ final weight - initial weight) $/$ initial weight. CF: condition factor $=100 \cdot$ final weight $/$ body length^3. *IW, initial mean weight $(g) ; F W$, final mean weight $(g)$.

\section{Intestinal morphometric and liver histopathological changes:}

Re-fed Nile tilapia with different dietary protein percentage after starvation revealed no significant changes in gastric, intestinal and hepatic structures. No pathological lesions or necrotic cells were observed in any of the examined organ sampled from each treatment group.

The gastric wall in all groups is composed of several tunicae: mucosa, submucosa, muscularis and serosa. Simple, straight, tubular unbranched gastric glands occupy most of the depth of the mucosa, and 
are lined with a single type of cell which has eosinophilic granules. Thickness of gastric mucosa decreased in starvation of Nile tilapia then increased by refeeding increased to be the highest in G4. Thickness of gastric musculature was significantly higher during starvation period than in refeeding period and in G1\&4 more than in G2\&3 (Figures 2 A\&B).

Light microscopy of intestine in all groups revealed a normal arrangement of columnar enterocytes, with an apical microvilli brush border, forming the epithelium of the mucosal folds. Villous height, peimeter and area were higher in three intestinal segments from all groups after refeeding than in starvation. Villous height increased un-significantly in proximal part from G4, significantly in middle part from G3 and un-significantly in distal part from G2-4. Villous perimeter and area were un-significantly higher in proximal part from $\mathrm{G} 4$, in middle and distal parts from $\mathrm{G} 2$.

Values of villous width increased after refeeding than in starvation only in proximal and middle parts; where it was the highest after refeeding in proximal and middle parts from G3 and in distal part from G2. Number of goblet cells was significantly higher in proximal part from G1 and in middle and distal parts from G4 than in other groups and more than its number in starvation period (Figures 3 A-E). Low and high GCs number in three parts of intestine was demonstrated in (Figure 4).

Light microscopic examination of liver from all groups showed polygonal hepatocytes that were aligned in cords separated by blood sinusoids. Each hepatocyte showed a distinct round and central nucleus with nucleoli and granular cytoplasm. Portal area contained hepatic artery, terminal hepatic vein and biliary duct. Exocrine pancreatic tissue (hepatopancreas) was present and was also surrounded by connective tissue but was separated from the liver cells by sinusoids containing blood vessels, both at the periphery and in interior of the tissue. Small H/N ratios were seen in starved fish. Gradual increase in $\mathrm{H} / \mathrm{N}$ ratio was recorded in G1 to G4 (Figure 5) indicating the increase in size of hepatocytes as shown in photomicrographs (Figure 6).

Many fish species have the ability to grow unusually fast after a period of diet deprivation or restricted feeding, and, in several cases, have caught up in weight with continuous-fed controls (Nikki et al., 2004; Wang et al., 2000).

The present data showed that the BW of starved fish was lower than refeeding fish fed different levels of protein. Also, CF of fish fed diet contained 28, 30\% was higher during refeeding than starved fish. However, CF of fish fed diet supplemented with $26 \% \mathrm{CP}$ was lower than starved control. Cho et al. (2006) observed that a relatively high relationship between CF and hepatosomatic index of starved olive flounder and duration of starvation as the decrease in weight, $\mathrm{CF}$ and hepatosomatic index of olive flounder probably resulted from utilization of energy in body needed for basal metabolism and maintenance for survival even during fasting. Indicating that, $\mathrm{CF}$ and hepatosomatic index could be a good index of starvation. Also, Abdel-Tawwab et al. (2006) observed a cessation of body and skeletal growth and a reduction of CF of fasting of Nile tilapia. Moreover, Rios (2002) found that significant decrease $(\mathrm{P}<0.05)$ in $\mathrm{CF}$ of traíra, Hoplias malabaricus, during the starvation period (30 and after 180 days) compared to control group. Those authors postulated that the constant length and decrease CF of starved traíra indicated that growth was stopped by food deprivation and endogenous reserves were mobilized in order to generate metabolic energy for maintenance. The relative changes in condition factor and liver weight are major indicators of physiological conditions and body loss caused by feed deprivation (Oni et al., 1983).

There were no significant differences in length of starved fish and refeeding fish fed diet supplemented with 26, and $28 \%$ CP. However, the length of refeeding fish fed 30 , and $32 \% \mathrm{CP}$ were lower than starved one. Gao and Lee (2012) found that length growth decreased gradually in starved Nile tilapia for one and two weeks and was negligible after 4 weeks of starvation and after refeeding, the length growth rate increased but did not exceed that of the control group. Starving animals give priority to the recovery of body mass over reproduction or structural growth (Kooijman, 2000). Also, Bavcevic et al. (2010) suggested that compensatory growth occurs selectively in body mass and not in length.

The Nile tilapia fed the diet containing 32\% CP had lower length and higher CF than that of other experimental groups. However, fish group fed 30\% CP diet had higher BW than other experimental group. There were no significant differences in BW between the Nile tilapia fed the experimental diet containing different levels of protein. With the same concept, Amalia et al. (2007) reported that the decrease in protein level was compensated by carbohydrate inclusion, without change in the dietary lipid 


\section{Egyptian J. Nutrition and Feeds (2015)}

levels in starved European sea bass (Dicentrarchus labrax). Moreover, Hemre et al. (2002) postulated that partial substitution of dietary protein by carbohydrates, in right forms and levels, can spare protein without affecting growth performance in most cultured finfish species. On contrary, Cho (2012) found that compensatory growth of olive flounder fed on both high protein and lipid diets rather than high lipid diet increase regardless of a week of feed deprivation. These results may be because the high protein diets greatly increasing the triiodothyroid hormone (T3) levels of fish that played an important role to achieve compensatory growth of fish (Cho and Cho, 2009). Also, Gaylord and Gatlin (2001) found the increasing dietary protein levels from $32 \%$ to $37 \%$ seemed to have desirable effect on compensatory growth of channel catfish (Ictalurus punctatus). Kim et al. (1992) reported that free amino acids in the body are supplied by dietary protein and catabolism of tissue proteins, and the free amino acids that are not used for protein synthesis and other essential functions are catabolized ultimately lo ammonia and the corresponding $\alpha$-ketoacids. The $\alpha$-ketoacids are used as an energy source or provide carbon for fat synthesis or gluconeogenesis. Amino acid oxidation is influenced by the level of protein and other energy sources in the diet, as well as time after feeding, or fasting.

In this study, we also studied the effect of starvation and refeeding of Nile Tilapia with different dietary protein percentages on gastric, intestinal and hepatic morphometric measurements. Starvation and re-feeding Nile tilapia showed a significant lower thickness of gastric mucosa in G1-3 while, it became significantly higher in G4 (32\% CP). Thickness of gastric musculature was significantly higher during starvation period than in refeeding period and in G1\&4 more than G2\&3. Re-feeding Nile tilapia with different dietary protein percentages could increase villous height, perimeter, area and number of goblet cells after starvation. The increase in the length of the villi implied an increase of the surface area for the greater absorption of available nutrients (Caspary, 1992). In addition, starvation was found to decrease size of the hepatocytes that gradually increased in size after refeeding simultaneously with the increase in protein $\%$ in the diet. It has been reported that starvation leads to a decreased cellular area and volume in hepatocytes, the appearance of a collagen fiber network, iron particle accumulation, changes in nucleus shape and position, reduced intercellular spaces and cell disorganization. With the same concept, Souza et al. (2001) reported a significant decrease in the area and volume of the cytoplasm and nucleus of hepatocytes from the food restricted fish group. However, the cytoplasmic area and volume returned to pre-restriction values only after 30 days of refeeding those authors suggested that the decrease in the hepatocyte cytoplasmic and nuclear; area and volume probably because of decreased anabolic and increased catabolic processes during food restriction. The liver cell alterations aggravated by starvation are also reversible (Storch \& Juario 1983; B hm et al., 1994). The morphometric parameters in liver cells indicated that Nile tilapia did not lose its capacity for physiological adjustment after the nutritional deprivation. Also, fish have developed this ability to recover in response to environmental fluctuation (Weatherley and Gill, 1987).

\section{CONCLUSION}

Fish BW of fish fed diet containing $28 \%$ \& $30 \%$ were significantly higher than other refeeding groups. CF revealed better values in fish fed diets containing $30 \& 32 \%$ of CP. Most of the measured morphological parameters were decreased by starvation except stomach muscular coat thickness. Refeeding, particularly, with $32 \%$ of CP resulted in increase thickness of stomach mucosa, villous height, perimeter, area, number of goblet cells and size of hepatocytes. 

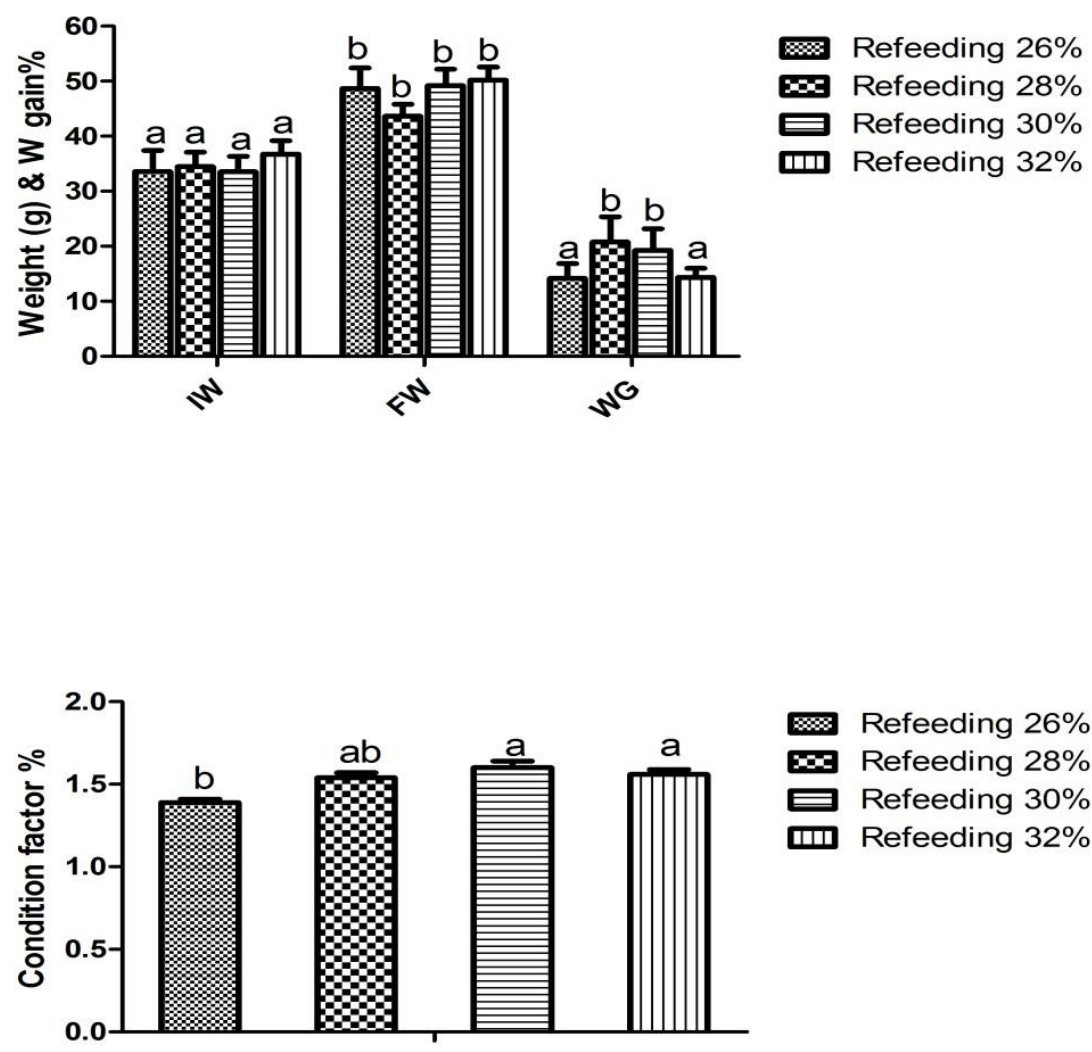

Fig. (1): Comparison between refeeding group fed supplemented different level of $\mathrm{CP}$ during the period of refeeding.

(A) Thickness of fundic mucosa

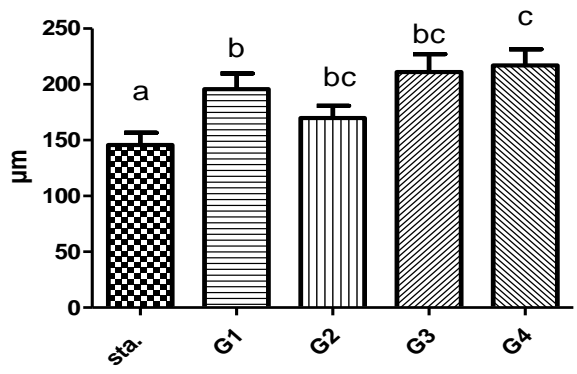

(B) Thickness of fundic muscle

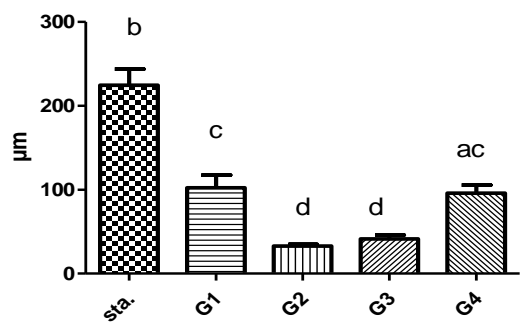

Fig. (2): Effect of starvation and refeeding Nile Tilapia (Oreochromis niloticus) with different dietary protein percentages on gastric morphometric measurements; A: thickness of gastric mucosa and B: thickness of gastric muscle layer. Superscript small letters in the same row are significant at $(\mathbf{P}<\mathbf{0 . 0 5})$. 
(A)Villous hight

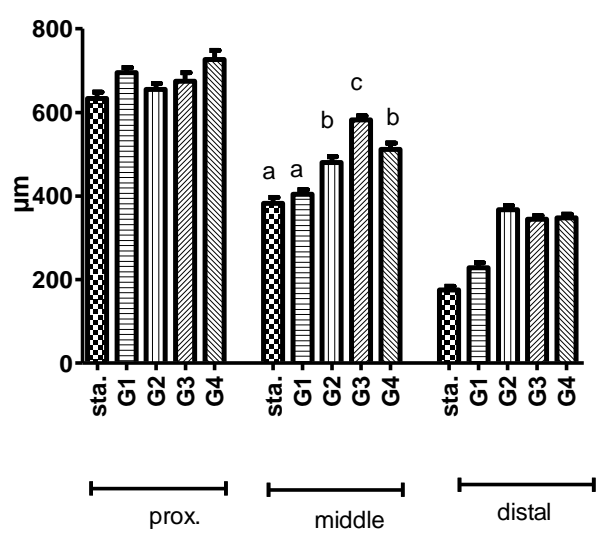

(C) Villous area

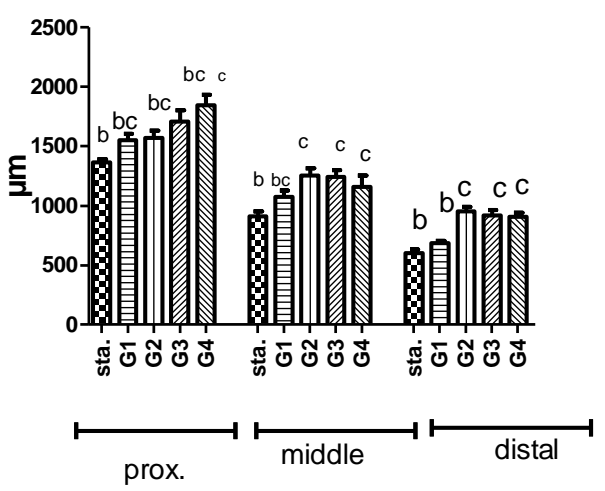

(B) Villous perimater

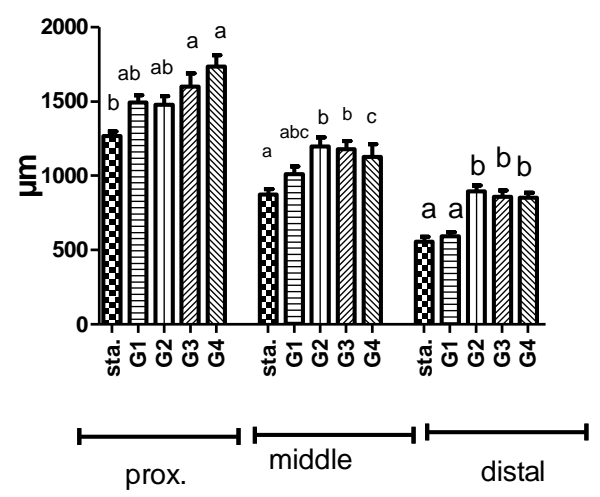

(D) Villous width

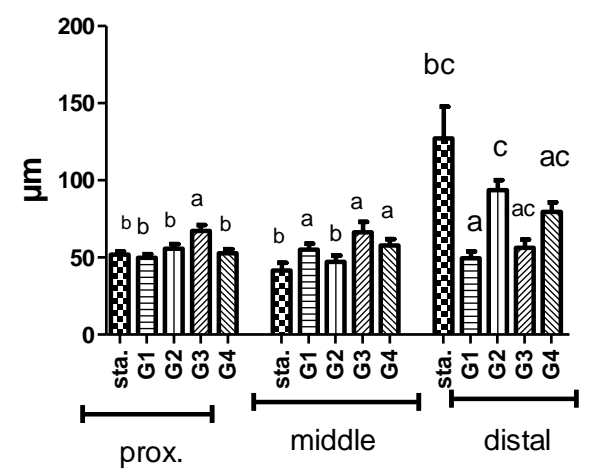

(E) Number of goblet cell

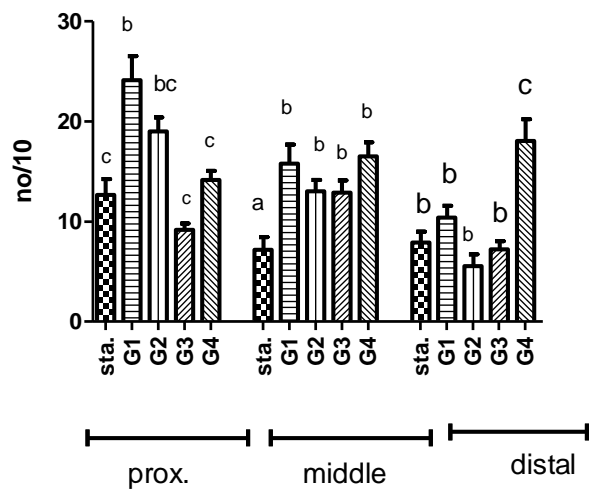

Fig. (3): Effect of starvation and refeeding Nile tilapia (Oreochromis niloticus) with different dietary protein percentages on intestinal morphometric measurements. Superscript small letters in the same row are significant at $(P<0.05)$. Sta=starvation 

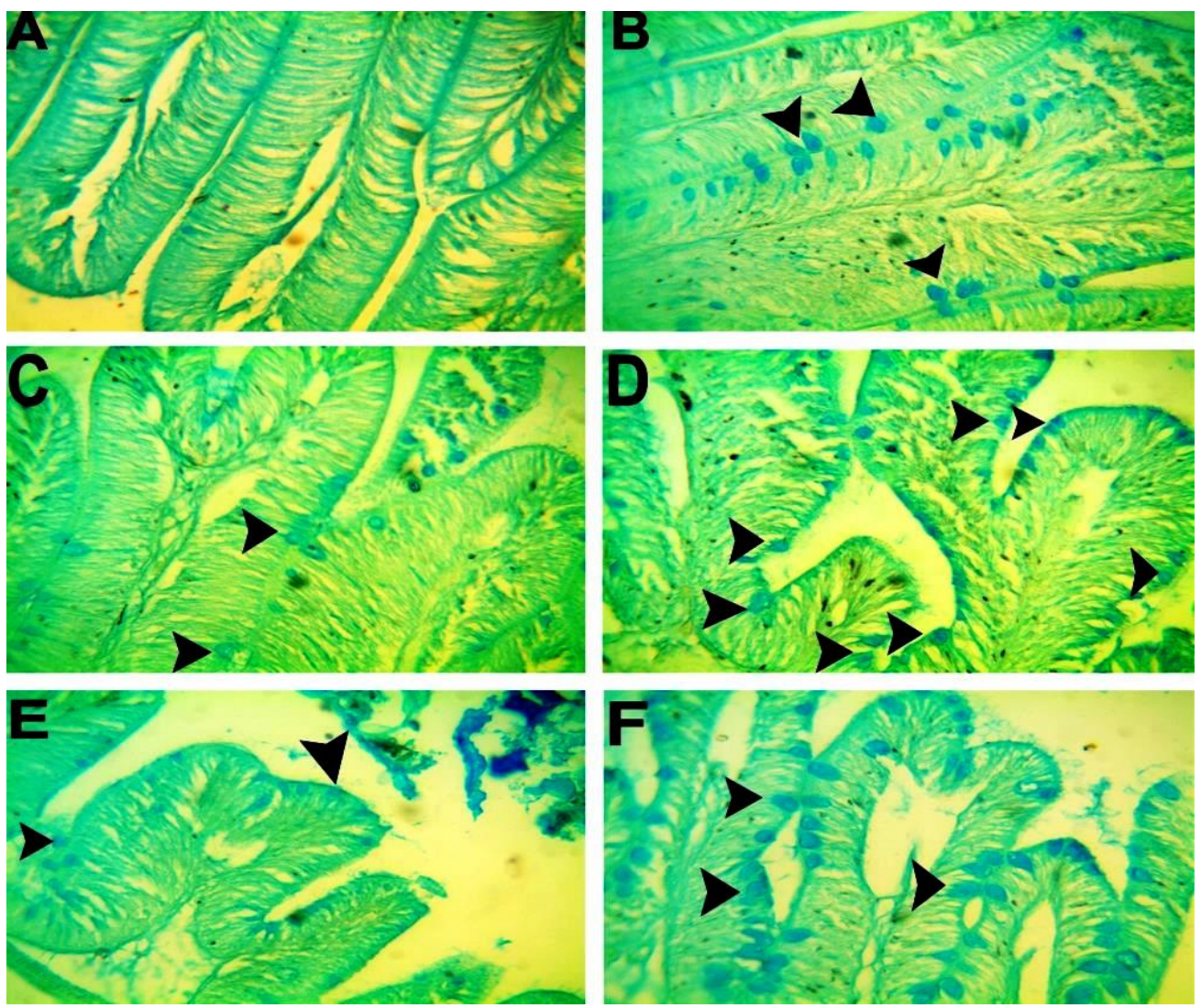

Fig. (4): Arrows point to GCs distribution in three parts pf intestine. A\&B: Proximal intestine with scant GCs in (A) and frequent GCs in (B). C\&D: Mid intestine with few GCs in (C) and frequent GCs in (D). F\&F: Low intestine with few GCs in (E) and frequent GCs in (F).

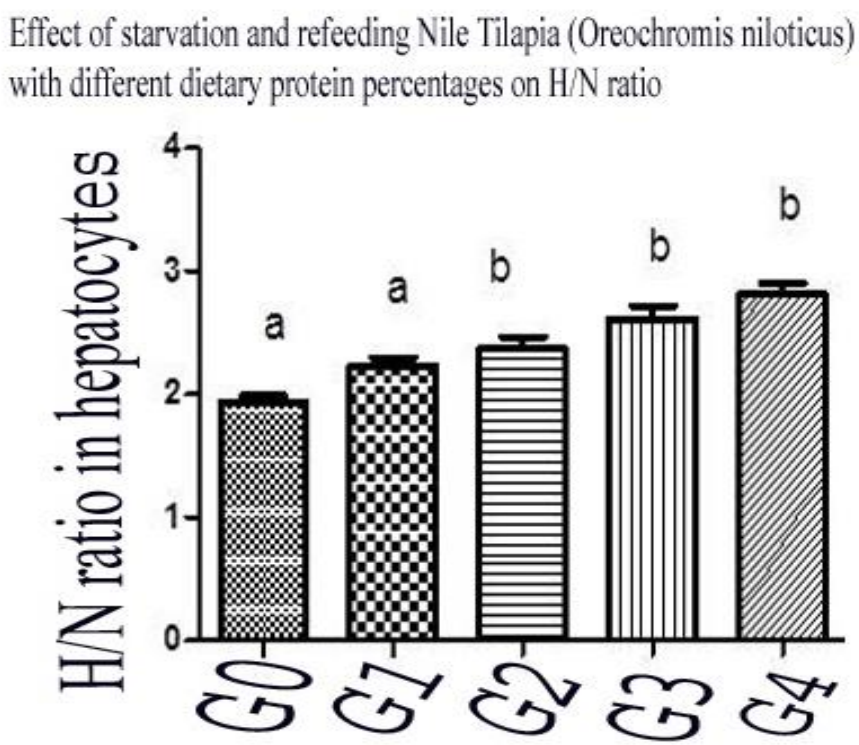

Fig. (5): Statistical analysis of values of $\mathrm{H} / \mathrm{N}$ ratio in different experimental groups. $A$ and $b$ indicate significance at $(\mathbf{P}<\mathbf{0 . 0 5})$. G0 $=$ period of starvation. 


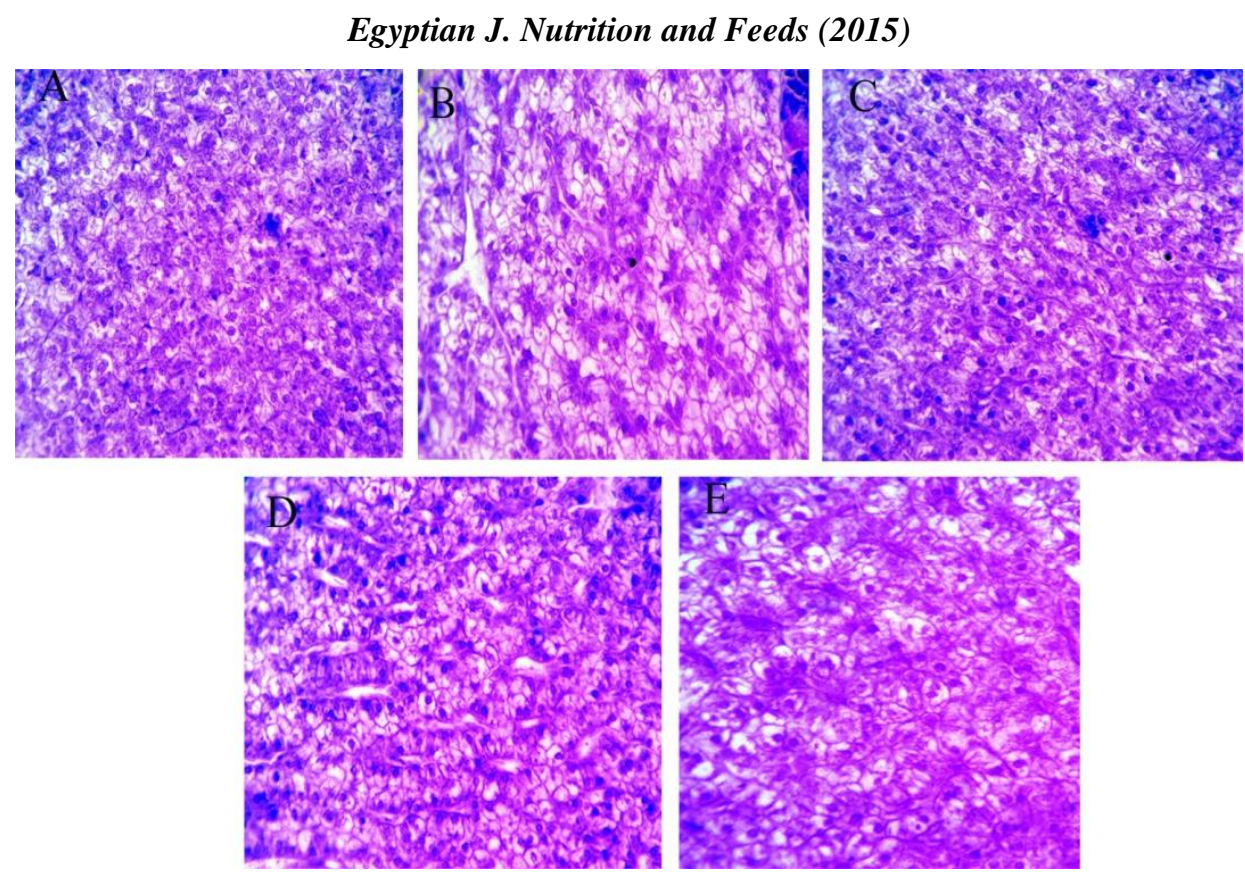

Fig. (6, A-E): Liver of Nile tilapia shows normal histology but with gradual increase in size of cytoplasm from G1 to G4 in photomicrographs (B-E) when compared to stavastion period in photomicrograph $\mathrm{A}$.

\section{REFERENCES}

Abdel-Tawwab M.; Y.A.E. Khattab; M.H. Ahmad and A.M.E. Shalaby (2006). Compensatory growth, feed utilization, whole-body composition, and hematological changes in starved juvenile Nile tilapia, Oreochromis niloticus (L.) Journal of Applied Aquaculture, 18(3): 17-36.

Amalia, P.J.; J.G. Maria; E.M. Amalia and O.T. Aires (2007). Metabolic responses to short starvation and refeeding in Dicentrarchus labrax. Effect of dietary composition. Aquaculture, 265: 325-335.

Bavčević, L.; T. Klanjšček; V. Karamarko; I. Aničić and T. Legović (2010). Compensatory growth in gilthead sea bream (Sparus aurata) compensates weight, but not length. Aquaculture, 301: 57-63.

Bedford, M.R. (1996). Interactions between ingested feed and the digestive system in poultry. J Appl. Poultry Res., 5: 86-95.

Bhm, R., W. Hanke and H. Segner (1994). The sequential restoration of plasma metabolite levels, liver composition and liver structure in refed carp, Cyprinus carpio. J. Comp.Physiol, 164(B): 32-41.

Caspary, W.F. (1992). Physiology and pathophysiology of intestinal absorption. American Journal of Clinical Nutrition, 55: 299S.

Cho, S.H.; S. Lee; B.H. Park; S. Ji; J. Lee; J. Bae and S. Oh (2006). Compensatory growth of juvenile olive flounder Paralichthys olivaceus L. and changes in proximate composition and body condition indexes during fasting and after refeeding in summer season. J. World Aquac. Soc., 37: 168-174.

Cho, Y.J. and S.H. Cho (2009). Compensatory growth of olive flounder, Paralichthys olivaceus, fed the extruded pellet (EP) with different feeding regimes. J. World Aquac. Soc., 40: 505- 512.

Cho, S.H. (2012). Effects of dietary nutrient on the biological index and serum chemistry of juvenile olive flounder Paralichthys olivaceus achieving compensatory growth. Fish Aquat Sci., 15: 69-72.

Cho, S.H. (2014). .Effects of Food Deprivation and Feeding Ratio on the Growth, Feed Utilization and Body Composition of Juvenile Olive Flounder Paralichthys olivaceus. Fish Aquat Sci., 17(4): 449454. 
Davis, K.B. and T.G. Gaylord (2011). Effect of fasting on body composition and responses to stress in sunshine bass. Comp. Biochem. Physiol. A. Mol. Integr. Physiol, 158(A): 30-36.

El-Sayed, A.M. (2006). Tilapia culture in salt water: Environmental requirements, nutritional implications and economic potentials. Eighth Symposium on Advances in Nutritional Aquaculture. November 1517, Nuevo Leon, Mexico.

FAO, Food and Agriculture Organization of the United Nations., (2009, 2007) FAO yearbook. Fishery and aquaculture statistics. http://www.fao.org/fishery/publications/ yearbooks/en.

Gao, Y. and J. Lee (2012). Compensatory Responses of Nile Tilapia Oreochromis niloticus under Different Feed-Deprivation Regimes Fish Aquat Sci., 15(4): 305-311.

Gaylord, T.G. and D.M. Gatlin (2001). Dietary protein and energy modifications to maximize compensatory growth of channel catfish (Ictalurus punctatus). Aquaculture, 194: 337-348.

Hayward, R.S.; D.B. Noltie and N. Wang (1997). Use of compensatory growth to double hybrid sun fish growth rates. Trans. Am. Fish .Soc, 126: 316-322.doi:10.1577/1548- 8659 126<0316:NUOCGT> 2.3.CO;2.

Hemre, G.I.; T.P. Mommsen and A. Krogdahl (2002). Carbohydrates in fish nutrition: effects on growth, glucose metabolism and hepatic enzymes. Aquaculture Nutrition, 8: 175-194.

Islam, M.S. and M. Tanaka (2004). Optimiztion of dietary protein requirement for pond reared mahseer, Tor putitora Hamilton (Cyprinformes: Cyprinidae). Aquac. Res., 35: 1270-1276.

Kim, K.I.; B.K. Terrence and H.A. Clyde (1992). Requirements for sulfur amino acids and utilization of D-methionine by rainbow trout, Oncorhynchus mykiss. Aquaculture, 101: 95-103.

Kooijman, S.A.L.M. (2000). Dynamic Energy and Mass Budgets in Biological Systems. Cambridge University Press, New York, US.

Marimuthu, K.; A.C. Cheen; S. Muralikrishnan and D. Kumar (2010). Effect of Different Feeding Frequency on the Growth and Survival of African Catfish (Clarias Gariepinus) Fingerlings. Adv. Environ. Biol., 4(2): 187-193.

National Research Council (1983). Nutrient requirements of warm water fishes. National Academic of Sciences, Washington, D.C. 102pp. Advances in Fish research Vol. 3. Fisheries and fish biology Research.

Nikki, J.; J. Pirhonen; M. Jobling and J. Karjalainen (2004). Compensatory growth in juvenile rainbow trout, Oncorhynchus mykiss (Walbaum), held individually. Aquaculture, 235: 285-296.

Oni, S.K.; J.Y. Olayemi and J.D. Adegboye (1983). Comparative physiology of three ecologically distinct fresh water fishes, Alestes nurse Ruppell, Synodontis schall Bloch and S. schneider and Tilapia zilli Gervais. J. Fish Biol., 22: 105-109.

Rios, F.S.; A.L. Kalinin; M.N. Fernandes and F.T. Rantin (2004). Changes in gut grossmorphometry of traira, Hoplias malabaricus (Teleostei, Erythrinidae) during long-term starvation and after re-feeding. Brazilian Journal of Biology, 64: 683-689.

Rios, F.S. (2002). Changes in metabolism rate and energy reserve utilization during starvation: Adaptation to long term drought periods. International Congress on the Biology of Fish. University of British Columbia, Vancouver, CANADA. www.fishbiologycongress.org.

Souza, V.L.; L.O. Lunardi; L.H. Vasques; L. Casaletti; L.S.O. Nakaghi and E.C. Urbinati, 2001. Morphometric alterations in hepatocytes and ultrastructural distribution of liver glycogen in pacu (Piaractus mesopotamicus HOLMBERG, 1887) during food restriction and refeeding Braz. J. Morphol. Sci., 18(1): 15-20.

Storch Vand, J. and V. Juario (1983). The effect of starvation and subsequent feeding on the hepatocytes of Chanos chanos (Forsskal) fingerlings and fry. J. Fish Biol., 23: 95-103.

Tian, X. and J.G. Qin (2003). A single phase of food deprivation provoked compensatory growth in barramundi Lates calcarifer. Aquaculture, 224: 169-179.

Wang, T.; C. Hung and D.J. Randall (2006). The comparative physiology of food deprivation: from feast to famine. Annual Review of Physiology, 68: 223-251. 


\title{
Egyptian J. Nutrition and Feeds (2015)
}

Wang, Y.; Y. Cui; Y. Yang and F. Cai (2000). Compensatory growth in hybrid tilapia, Oreochromis mossambicus $\times$ O. niloticus, reared in seawater. Aquaculture, 189: 101-108.

Weatherley, A.H.; H.S. Gill (1987). The Biology of Fish Growth. Academic Press: London.

Wieser, W.; G. Krumschnabel and J.P. Ojwang-Okwor (1992). The energetics of starvation and growth after refeeding in juveniles of three cyprinid species. Environ. Biol. Fish, 33: 63-71.

Zhu, X.; S. Xie; Z. Zou; W. Lei; Y. Cui; Y. Yang and R.J. Wootton (2004). Compensatory growth and food consumption in gibel carp, Carassius auratus gibelio, and Chinese longsnout catfish, Leiocassis longirostris, experiencing cycles of feed deprivation and re-feeding. Aquaculture, 241: 235-247.

تأثير تجويع وإعادة التظذية علي علاثق تحتوي علي نسب مختلفة من البروتينات علي النمو التعويضي والتنيرات الهيستولوجيا في البلطي النيلي

\author{
عبير السعيد عزيزة'، ولاء عوضين2، ايمان زهران3 و طارق ابراهيم1

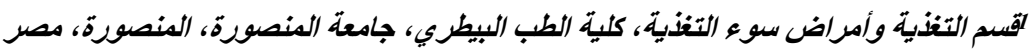

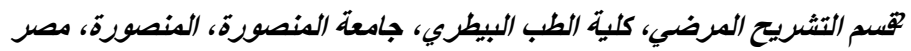

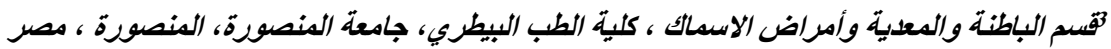

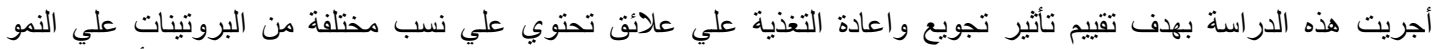

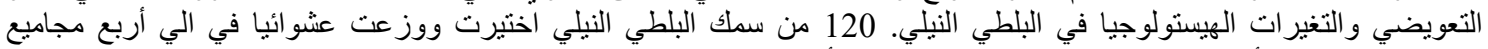

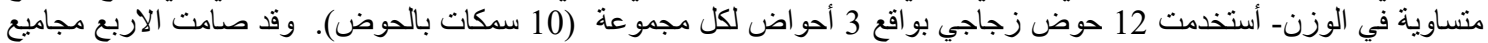

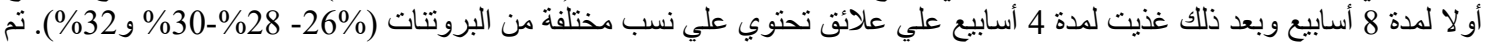

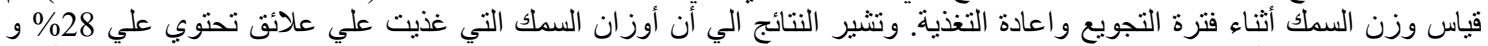

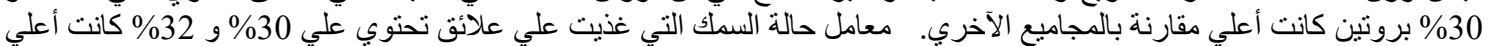

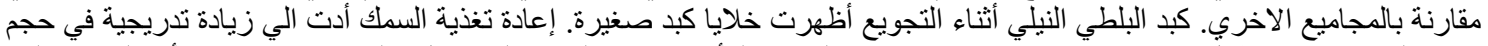

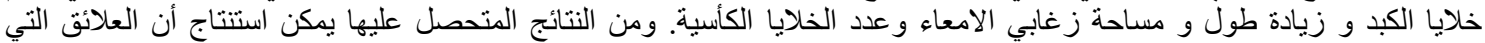

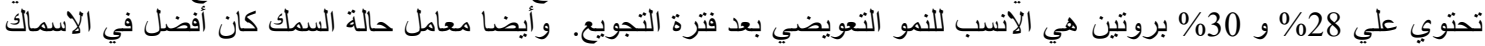

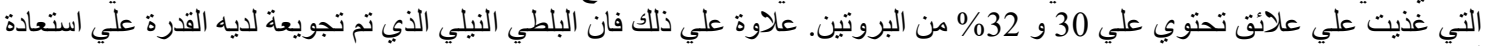
أنسجة الكبد الطبيعية بعد فترة من اعادة التغذية. 